\section{EIS 11/2017}

The Pros and Cons of Integration VS. Disintegration Scenarios for Europe

Submitted 04/2017

Accepted for publication 08/2017
The Pros and Cons of Integration VS. Disintegration Scenarios for Europe

\section{Stanisław Umiński}

The University of Gdańsk, Research Centre on European Integration ul. Armii Krajowej 119/121, 81-824 Sopot, Poland

$\Gamma$ crossef http://dx.doi.org/10.5755/j01.eis.0.11.18955
Abstract

\section{Introduction}

\section{ktU}

European Integration Studies No. $11 / 2017$

pp. 8-18

DOI 10.5755/j01.eis.0.11.18955

(C) Kaunas University of Technology
The purpose of the study is to discuss the ongoing debate on the future of the EU, with reference to the scenarios formulated by the European Commission, as well as other interesting concepts, and to indicate the most probable scenario that the EU would follow. The method used in the research is studies of the scientific publications, comparison and evaluation of alternative integration scenarios and interpretation of selected legal issues related to the division of competences between the EU and the Member States (MS). The main tasks are as follows: (i) to prove that the concurrent debate about the future of the EU is not "new" and similar questions were asked since the birth of the integration processes, (ii) the usage of sovereignty concept to interpret different demand for integration of the MS, (iii) identification of links between globalisation, integration and the crisis as well as (iv) comparisons of different scenarios related to further (dis)integration within the EU and their consequences. The novelty of the paper is that it relates the integration scenarios formulated by the European Commission to the issue of sovereignty as well as to historical and legal background of the European integration.

Out of the possible scenarios proposed, multi-speed Europe is the most probable one. The real challenge, if this scenario will evolve, is to safeguard the possibility for the "lagging countries", to join the (more integrated) leaders - if the former will be ready to do so. The challenge is to make the multi-speed Europe - an inclusive concept. Multiple speeds have in fact existed within the EU, as there always have been and will be those who are the laggards and the leaders.

The awareness of the European issues has been increasing, as suggested by De Wilde $\&$ Zürn (2012). However, the EU will go through serious changes, consequences of which deserve thorough debate in order to disseminate knowledge on the consequences of the strategic choices ahead of the MS.

KEYWORDS: future of the EU, integration scenarios, sovereignty, globalisation.

The 60th anniversary of the Treaty of Rome seems to be a perfect time to make some reflections about integration within the EU. The time for discussing the pros and cons of integration vs. disintegration scenarios is special, as the "climate" for making a debate on the integrational issues - has changed.

Crisis "2008+" and its consequences undoubtedly are key factors, negatively influencing the perception of the EU integration. Their consequences for the economies of the Members States (MS) of the EU and their societies turned out to be so serious, that also have weakened the fundaments of the European integration. National egoisms have increased, the solidarity among MS has been weakened, moreover the crisis in not only complex but also multidimensional (Tosun, 
Wetzel \& Zapryanova 2014). The 2004 and the next enlargements of the EU resulted in its increased diversity. New and old MS often have different interests. They differ in many aspects: GDP per capita, purchasing power, democratic traditions, rule of law, quality of institutions, institutional and administrative transparency etc. Many differences have clearly revealed also among the old MS, an example being competitiveness inequalities between the southern and the northern countries. The EU is under the immigration pressure, that has its external and internal dimension, the latter stemming from the enlargements. Last but not least, the globalisation pressure shall be mentioned. The EU (and the integration process thereof) is perceived as a "transmitter" of the globalisation's negative consequences, to the MS.

The discussion on the EU's troubled situation and its unclear future might be perceived to be as intensive as it has never been before. This perception relates both to the debates taking place in the particular MS, as well as on the European level. Moreover, the so-called negative cumulative causation has been initiated, which means that negative opinion about the EU brings the next even more critical one. However, the exchange of views about the desired direction towards which the integration process shall go - is not new. From the very beginning, the conflicting ideas about the shape of the integration process have been confronted.

For instance, after the Second World War, during the Congress of Europe in Hague in 1948, different attitudes towards integration were presented. Some of them were deeply rooted in the federalist-oriented ideas, while others, envisaged intergovernmental cooperation, that only to the limited extent shall transfer the prerogatives towards the supranational (community) level. However, it was the sovereignty question that was a real issue of the debate. One can argue, that the today's debate on the future of the integration project is different. Undoubtedly, the MS are far deeper integrated within the EU. Integration process went through several stages, from the free trade area, through customs union, common market to incomplete economic and monetary union. What needs to be stressed, is that in each period, the political, as well as historical context, constitutes the framework for the discussion about the further integration. Refereeing to the functioning of the market mechanism and its "language", the so-called demand for integration is determined by this framework. It sets the "fears" associated with the next integration steps. Today, we, for instance, fear globalisation-related issues. The workplaces for the EU citizens are endangered by the competitors not only from China, India and other low-cost countries but also from Canada, Japan etc. However, when we come back to the ideas of the Founding Fathers of the European Communities, they meant French-German cooperation, as a fundament of the future integration process. Was it not a revolutionary, astonishing idea - at that time, just after the Second World War? Two, traditionally conflicted countries, Germany and France, working together in order to establish the communities.

Today, as well as in the foundation years of the European integration, the issue to be decided has been the same. It is the scope of the transposition of the nations' competencies to the common (supranational) level. Therefore the problem has been to what extent a country is willing to limit its sovereignty, in order to benefit from being integrated with other countries and being able to influence their sovereignties.

Integration influences sovereignty. However, the understanding on how the sovereignty is altered - depends on one's worldview. Sovereignty can be limited, as a country in a voluntary way decides to get rid of part of its sovereignty - and share it, with other countries. Therefore a shared (or pooled) sovereignty is built. Through sovereignty sharing, a country gets influence over other countries' sovereignty. Thus, reducing of sovereignty, paradoxically, at the same time,
The subject of the integration debate is not new

\section{The sovereignty in the EU}


broadens it. The judgement of the final balance of what the country losses (or sacrifices) and gets in exchange, being integrated with other countries - is difficult to be assessed. In the sphere of economic relations, cost-benefit balance is easier to be accomplished. However, many integration-related aspects belong to the symbolic sphere, and their valuation depends on ones' worldview, life-experience, family tradition etc. The assessment can be situated somewhere on the whole spectrum between the cosmopolitan or national-oriented extremes. Each individual may have his or her own, particular scope, to which sovereignty can be limited or shared.

Another question is if sovereignty shall be treated in absolute (zero-one) terms, meaning that it is completely unrestrained or, alternatively, completely lost. Or it is allowed that part of sovereignty can be shared. Historical legacy, political system (centralisation vs. decentralisation) and societal environment that influence current political situation - all determine the willingness to share sovereignty. The concurrent economic situation and societal environment are more important, that apparently one could think. The correlation between the dynamics of the integration process and the business cycle trends is observed since the European integration has been initiated in the 50ties last century.

A tendency to treat sovereignty in absolute terms can hardly be justified. As the world economy has become globalised, the activity of transnational corporations, capital and services flows and openness to trade - contribute to sovereignty limiting. It is not necessary that a country becomes the member of the EU, that its sovereignty is limited. However, being part of the EU and its legal system, with the supremacy of the European law over the MS' laws, reduces sovereignty even more.

All the more, monetary integration is perceived as the most sovereignty limiting aspect of integration. However, as a country is open to free capital transfers and its banking sector can be penetrated by foreign direct investment, it reduces the monetary policy independence. A country that is not in the Eurozone, conducts independent monetary policy (it is run by the central bank). In an open economy, however, effects of this policy often "leak" to the markets of the other countries. The increased demand, due for instance to the reduced interest rates, can be directed towards imported products. If foreign owners are active in the banking sector, and the important share of the banking assets are foreign owned, it may reduce the efficiency of the "independent" monetary policy. The Central bank sets the interest rates, that influence demand for credit. However, foreign-owned banks' preferences in the credit policy, might be not compatible with the policy of the central bank. For example, a bank can tighten its credit policy, because of the consolidation process, meaning that capital is transferred to the banks' subsidiaries in the other countries. Bank can also disfavour some industries from being intensively credited, as they have been ranked high risk. Sovereignty is thus an elusive concept. Due to participation in dense, global trade and capital flows networks, a country is far from being absolutely sovereign.

The division of competences between the EU and its MS is declared in the Treaties. Article 5 of the Treaty on the European Union (TEU) sets the limits of the EU competences, according to the principle of conferral. Also, the principles of subsidiarity and proportionality apply. The EU's ability to act, or to interfere into the Members States economies, is not unlimited. As a rule, if competencies have not been conferred upon the EU, they remain with the MS. Article 5 of the TEU describes the subsidiarity principle. According to it, the EU is entitled to take actions in areas that are outside its exclusive competences, if the objectives can be more sufficiently obtained by the EU than by its MS, acting individually. It requires the condition to be fulfilled, that the union level of intervention, by reasons of effects or scale, is more effective. Proportionality rule shall be obeyed, guarantying that the EU action does not exceed what is necessary for the achievement of the objectives formulated in the TUE and the Treaty on the Functioning of the EU. 
One of the Treaty of Lisbon aims and changes brought by was the increased role of the national parliaments in the decision-making process in the EU. The task of the national parliaments is to ensure compliance of the EU actions with the subsidiarity principle. Another question is if the so-called yellow card procedure effectively protects the MS from "excessive" EU law interference into their sovereignty, which would signal the non-compliance with the subsidiarity principle.

The above-presented divagations on sovereignty, its limits or changes in countries of the EU shall be done, with reference to the ideas formulated by the Founding Fathers of the European integration process after the Second World War. Robert Schumann, Jean Monnet, Alcide de Gasperi, Paul-Henri Spaak and the others, understood integration as a process leading to peaceful coexistence of nations. Limiting their sovereignty and transferring some prerogatives to the supranational level through the creation of federal bonds - was the way to achieve it.

$2008+$ crisis proves, that the dynamics of the integration processes in the EU and its predecessors, has been highly correlated with the economic cycle trends. This correlation is not something that revealed itself suddenly. An inquiry into the history of the European integration leaves no doubt about it (Jovanovic 2005; Baldwin \& Wyplosz 2004). Integration was developing in waves. After the Second World War, it was a climate for a radical change. The economic rebuilding process was accompanied by optimism. The high dynamism of the economic growth stemmed from the huge destruction, caused by the Second World War. The 70thies of the last century are today referred to, as the Eurosclerosis. The EU competitive position deteriorated and both, high inflation and unemployment (stagflation) - coexisted in the MS. The Eurosclerosis - to large extent - was the consequence of the world economy crisis, that revealed the EU structural weaknesses. In the 80ties, the increased dynamism of integration process correlated with the liberal revolution in economics and with a trend towards privatisation and deregulation. The liberal paradigm and liberalisation resulted in a long period of economic prosperity and dynamic growth. However, liberalisation of financial markets constituted the "seeds" for 2008+ crisis. The evolution of sophisticated, risky financial instruments has led to the crisis in the autumn of 2008. Collateral debt obligations (CDOs) exemplify, how the risk spreading was understood in an opaque way, bringing misery to the "ordinary people". 2008+ crisis can be interpreted in many ways. One of them is the serious discrepancy between the financial markets and the "real" economy (Ortowski, 2016). In times of the favourable economic situation, there is a tendency to liberalise and open the economy to foreign competition, also from the other MS. However, when economic situation deteriorates, the tendency to limit integration scope or its dynamics - comes back.

As already mentioned, the perception of the European integration is that it brings instability to the economies of the MS, also as it transfers the negative impulses stemming from globalisation. It is a paradox because the integration was intended to bring stability. For instance one of the aims of the monetary integration was to eliminate the currency rates fluctuations. The introduction of euro brought stability, as there is no currency risk for transactions done in euro. However, it resulted in macroeconomic instability for some MS.

The key problem seems to be the broken link between prosperity for the next generations and integration processes. Membership in the EU does not automatically guarantee the improved quality of life for the next generations, and high unemployment among the young people in the EU MS indicates it. Convergence - is not an automatic process in the EU. The endogenic theory of economic growth is less optimistic than the neoclassical growth theory, that envisaged "automatic" convergence, resulting from diminishing marginal productivity and catching up processes. The message of the endogenic theory of the economic growth is different - convergence is conditional. It happens in clubs (club convergence). Steady states can differ - for each of the clubs.

\section{Integration, globalisation and consequences of the crisis}


The fundamental question is to what extent the integration process by itself has contributed to the situation of having no hope for economic prosperity in the EU. Is the situation in the southern UE MS so serious because they were conducting irresponsible economic policy? Or it is so because the Eurozone was constructed in a way that results in macroeconomic imbalances, as the criteria of the optimum currency areas have not been fulfilled? Answering questions of that type goes beyond the scope of this article.

The key problem, today, as the future of the EU is discussed, seems to be that for the younger generations of the EU citizens, the EU is perceived as a "construction" that brings troubles, instability and rigidities. They do not remember that the European integration was meant by the Founding Fathers as a remedy to the military conflicts. Thus, if the younger generations do not have this war or post-war experiences, they question the integration process so easily. They treat peace as granted and see the EU only as a "trouble maker".

As already mentioned, the discussion about the scenarios for the further integration - is not new. Its key element is if more of the federative component is needed. Or - treated in the opposite way - if the troubled situation in the EU (after the UK has decided to quit the EU) is a result of "too much" of the federal content, and therefore federative approach shall be limited.

To make the further elaboration less "theoretical", more important, already formulated scenarios will be presented in the remaining of the paper.

The key document, that shall be commented, is The White Paper, published by the European Commission in March 2017 (European Commission, 2017). It describes 5 scenarios for EU27 (after the UK quits), by the year 2025. As a background, The White Paper describes the drivers of the EU's future, including important facts about a place of the EU in a changing world. The EU27's share in the global GDP has been shrinking, other currencies than euro, are gaining in importance as global currencies, the recovery after the 2008 recession is not evenly distributed among the MS and the EU is facing the ageing challenge. The challenges for the EU are predominantly acute for the young people, for whom the better well-off than for their parents - is not guaranteed. Also the terrorism, militarisation of the world and Russian troops on the EU Eastern border - are the factors that constitute the challenges for the EU's MS, acting together.

The scenario 1 is based on the "carrying on" attitude. The EU "sticks to its course"; what has been done so far, would be improved or upgraded. The focus will be on improving the functioning of the single market and on the creation of jobs, stimulation of economic growth and investment. The pros of scenario 1 are sustaining of the unity of the EU27. However, if the EU is criticised for its so far achievements or failures, this scenario does not offer any chance to make a serious and expected change, whatever would be understood by a change.

Scenario 2, "nothing but the single market", represents a "step back". The progressing integration, evolving according to "an ever closer union" rule, is stopped under the conflicting interests of the MS. Differences among the MS are possible in many spheres. National - instead of the commonly set - regulations apply for instance to the social and environmental standards, as well as to the public aid etc. Bilateral cooperation gains in importance. The main drawback of such a scenario is that the EU will not make use of collective action, which would limit its bargaining power in the world.

In scenario 3, "those who want more do more", many coalitions of the "willing" countries would arise. Over time, the lagging countries will have the possibility to join the "willing more" countries. The UE's overall transparency will suffer from many possible, strengthen cooperation circles that would be formed. Transparency of the decision-making process will deteriorate. 
In scenario 4, "doing less, more efficiently", the integration will be focused on the limited, selected policy areas, however, the EU will act quicker and more effectively. A step back in integration will be in those areas, that will be regarded as less important. This scenario means less solidarity between the MS. For instance, the regional/structural policy may be the neglected area. The different priorities of the MS may make it difficult to decide which are the areas in which the EU shall do more or less.

Scenario 5, "doing much more together", envisages that further than ever before, deep cooperation between all the MS would evolve. The EU will face the global challenges "as one". The defence and security will be prioritised. A strong focus would be on the coordination of many aspects of economic policies (taxation, social matters, financial supervision systems etc.). Such an EU would be quicker and more efficient, however those who are opposite to such a deep federalist approach - would feel being alienated in the EU.

The two extreme scenarios are 2 and 5 . Number 2 would be a serious step back, many European level policies would be rolled back, the EU (or precisely the European Commission) will withdraw from pushing ahead the integration of policies or better economic governance, for instance in the Eurozone (Janning, 2017). The scenario number 5 seems to be leapfrog, in which all the MS want "more of Europe". As noticed by Janning (2017), the White Paper does not represent usually presented "binary logic", in which only two opposite scenarios are possible, which are decay vs. progress. The White Paper seems to be an invitation to a debate on the future of the EU, in the global, changing world. This debate is important for the MS and their citizens, because the EU structure will probably seriously change and the politicization of the EU-related issues is a fact reflected in increasing awareness and polarization of opinions (De Wilde \& Zürn, 2012).

Many terms, describing the possible ways in which integration would evolve, could be quoted or recalled here: concentric circles of integration, multi-speed Europe, two-speed Europe, Europe a la carte, variable geometry, etc. It seems, however, that a relevant term is a flexibility. Flexibility is a solution to reconcile different - often conflicting attitudes - towards the EU's future. Flexibility was in fact introduced to the acquis communautaire by the Treaty of Amsterdam, signed in 1997. Enhanced cooperation (or closer cooperation) envisaged in the Amsterdam Treaty, however, was not successful.

Grabbe and Lehne (2016) see the main challenge for the EU in solving the puzzle how to provide two issues in the long run: internal cohesion and flexibility. The challenge for the EU is twofold. In the globalised, changing world, the EU must be stronger, more integrated in order to be able to cope with the challenges ahead of it. However - it must be cohesive, which means the imperative to contain many centrifugal forces. Grabbe and Lehne (2016) formulate several recommendations as regards flexibility. According to the Authors, the EU shall protect the single market integrity, shall punish noncompliance, consolidate the Eurozone project, allow flexibility in new areas and use flexibility in order to develop relations with third countries in a creative way.

Cantore (2011) treats enhanced cooperation as a tool enabling the balance between unity and asymmetry. Enhanced cooperation, or flexible integration, is a step towards multi-speed integration. In the EU that consists 28 countries, the tension between sovereignty and closer integration is unavoidable. Flexible integration undermines the unity of the European "construction". It may result in centrifugal tendencies - therefore may not be accepted by some of the MS. However, as noticed by Cantore (2011, p. 18), "asymmetry is in the DNA of the European Union" and was present in all the stages of the integration process.

It is difficult to judge and unequivocally say how the finalite politique of the EU in the forthcoming years would look like. However, it is clear, that political discussion has already started. The political leaders of the "big four" (France, Germany, Italy and Spain) at the meeting on the 6th of March, 
made a strong signal in favour for the multi-speed integration, with intensified efforts towards the deeper integration within the eurozone, which would reduce the functional dissonance due to the incomplete economic and monetary union (Niemann \& Ioannou, 2015). The message from the "big four" meeting is that:

_ despite the opposition of the countries not willing to integrate deeper, the integration process must forge ahead; otherwise, the EU is at risk of disintegration,

_ a Europe of different speeds is a necessity, otherwise, the EU would probably "get stuck". Shall this occur, the European efforts in favour of peace, may be endangered,

- "unity does not mean uniformity", as declared by Francois Hollande, meaning that new forms of deeper (or enhanced) cooperation shall enable for the willing MS to push integration ahead (Zalan, 2017).

As a multi-speed concept is so strongly promoted, it deserves more attention and presenting its pros and cons.

The main arguments against multi-speed Europe can be described as follows:

_ it may lead to the further divisions within the EU, MS will not be treated equally. It seems unavoidable that some MS will be "in" or "out". All the more, it is hard to predict what "in" or "out" they would be, as many functional spheres of MS' cooperation could evolve;

- it will dismantle solidarity, as those how will become outsiders, will not be able to take part in the core of the decision-making process. In multi-speed Europe, many coalitions would be possible, which will be detrimental for solidarity,

- it would make the decision-making process even more complex than it is now. Structures within structures will arise, competencies would overlap, etc. The federalists will not accept it. They would prefer to have transparent, coherent structure of the EU.

The main arguments for multi-speed Europe can be described as follows:

_ the sceptics, shall not be able to slow the integration processes down. Those who want to integrate closer, to be an avantgarde and wish to build the stronger union - shall have a chance to do so,

- multi-speed EU is nothing new, the EU has been functioning with multiple speeds for long, the examples being many opt-outs (also for Poland: Charter of Fundamental Rights), for the UK and Denmark (not in the Eurozone),

_ MS are different, for instance not all of them "fit" into the Eurozone, as their competitiveness differ, inflation rates are not the same, some of them need devaluation of currencies from time to time etc., their economic policies can hardly be harmonised (debating Europe, 2017).

The multi-speed concept is intended to make the EU more efficient, dynamic and capable of facing its challenges. However, this scenario represents "more of Europe" option, at least for those, who agree on more integration. It can be criticised however on the following grounds: if the European project that has been functioning so far - has failed, "more integration" - seems not to be a reasonable remedy. Friedman (2015) for instance, is of the opinion, that the concurrent EU crisis is the crisis of brotherhood. If his diagnosis is true, therefore multi-speed will not be a remedy for the EU. Multi-speed means less solidarity.

Zielonka (2014) formulates several scenarios of the disintegration of the EU. He arguments, that the crisis, that the EU is going through now, is far more serious than the past integration crises. Its nature is not financial or "technical", related for instance to the indebtedness of the MS etc. The crisis is about the EU cohesiveness, trust and imagination. Zielonka (2014) refers to the concept of medieval empires. He sees the remedy for the EU's crisis not in bringing competencies 
back from the EU/supranational level to the MS. MS, by their citizens, are also perceived to be inefficient. The Medievalism concept assumes that different authorities overlap and share the competencies, which leads to sovereignty pooling and overlapping. The special role is envisaged for global cities and agglomerations. The scenario proposed by Zielonka is not exactly resignation from integration, but rather building it according to the new rules. Competencies and power shall not be assigned according to hierarchical structures and sophisticated treaties. Instead, a functional network of cooperation is proposed. Instead of the current paradigm, that is monophony, Zielonka (2014) proposes "polyphony", represented by interplaying actors from the European level, national levels, cities/agglomerations as well as civil society level.

An interesting contribution to the discussion on the future of the EU was done by Piketty (2016). He sees the main drawback in the functioning of the EU in the fact, that it does not temper the dangerous and harmful "experiments" of the global capitalism, as it was intended to do so, by the Founding Fathers. Moreover, the monetary integration, in the form as it was established within the EU, is not a panacea for the economic problems of the MS. It makes the problems stemming from globalisation to be even more severe. As a reform, Piketty (2016) proposes to establish a strong parliamentary representation of the Eurozone's MS. Also, a separate budget shall be made for the Eurozone countries, "supplied" from the European tax. It would enable to fulfil "taxation with representation" principle. Eurozone would become a fully-fledged currency union, with not only monetary policy but also with strong, common institutions and harmonised taxes and economic policies. Some part (10 percent) of the harmonised corporate income tax would be collected at the federal level. Harmonisation of taxes would reduce harmful tax competition. Communitisation of MS's public debts will be done, which will help the highly indebted MS (as Greece, for example) to pay their debts more easily. Communitisation of public debts means lower interest rates for the less creditworthy, southern MS. As pointed out by Piketty, and worth recollecting at the 60th anniversary of the Treaties of Rome, after the Second World War Germany's debts were reduced. Therefore the idea of helping the indebted MSs to overcome their debt problem - deserves serious attention.

The reform of the EU proposed by Piketty, in fact, would mean multi- or two-speed Europe. It would be designed as the one to be opened for the next "willing" MS. However due to political reasons it does not guarantee to be open for the next MS - in the future. Thus the question is if it will be an inclusive or exclusive project.

Guerot (2016) proposes even more "radical" solution for Europe, however sharing some elements of the Zielonka (2014) proposal. She treats cities and regions as a source of European identity, not countries. Therefore, despite the fact that the EU is in crisis now, it makes sense to discuss and introduce the concept of the European Republic. The idea of the European Republic is consistent with the thoughts of the Founding Fathers, that treated the European project as an alternative for particular MS' nationalisms. The true challenge for the EU is to face the competitive pressure from China, USA Russia etc. The normative unity is required, that would be provided by the European Republic. On the other hand, the identity and diversity - are provided by cities and regions.

\section{The pros and cons of possible scenarios and dynamics of integration}

The above-presented ideas and scenarios reveal only the fragment of the ongoing debate related to the future of the integration processes in the EU. Each of them has pros and cons. The discussion has just started, new European architecture will be worked out. Each MS will have to decide, what option to support, and what "sort of Europe" will suit its interest and fit into its "demand for integration" better. The outcome is - yet - hard to predict. Political agenda influences the climate for the European debate (French presidential elections in May 2017 and German elections in October 2017). However one thing seems clear, the EU will change. 
One of the solutions proposed is the new treaty for the EU, to be negotiated by the MS. This, however, seems to be a long term perspective, very unlikely in the short run. It seems to be a risky proposal to follow, as the final outcome is highly unpredictable and may by far away from expectations of particular MS. Those who postulate "less integration" option, might be dominated by those, who put an option on the EU to be even more integrated. According to Buras (2013), an intergovernmental method of integration (more suitable for multi-speed Europe solutions) is more likely - than negotiating the new treaty. The so-called new intergovernmentalism is already present in the EU, especially after the beginning of the financial and economic crisis in 2008. Such a solution, however, leads to the establishment of the new union (or unions), parallel to the existing one. It may result in the increased tensions between the MS, as the role of the EU institutions will be weaker. First of all the tension between the Eurozone vs. non-Eurozone MS are likely to increase. Paradoxically, the economic and monetary union, despite the fact it's architecture is not completed, did not implode, but will probably integrate furtherly even deeper (loannou, Leblond \& Niemann 2015).

A risk for MS that are not keen on federal solutions, as described for instance in scenario 5 from the White Paper, is that if they stay out of the core, will suffer from less solidarity. Less solidarity means less influence on the decisions taken by the core countries, probably fewer funds available from the EU budget, less transparency of the functioning of the EU as a whole. The question is however what is the priority of the MS. If this is safety, broadly understood also in the military sphere, then strong focus on federalisation shall be more easily accepted by the MS. Thus the issue is not to change the UE into the union of the sovereign, or independent states, but of the safe states. The MS are coexisting in the strong symbiosis, stemming from economic relations. A stress shall be on safety, that safeguards the sovereignty.

In the "strong, disintegration" variant, if for instance the EU would be limited only to the single market, without common policies and even without common currency - the situation of less developed, less competitive MS would not be comfortable. This scenario is not very likely - the Eurozone brings many benefits for Germany, therefore more expected is tightening integration within the Eurozone. Nevertheless, we can try to sketch some of the most important consequences of such a hypothetical scenario.

This scenario would mean that MS would be able to act individually in the sphere of economic policies. For instance, in the absence of common competition policy, those who can afford it, would subsidise their domestic producers more. The less well-off MS will have no chance to compete in the race for subsidies. The subsidised products from other MS would be a serious competition for domestic producers. As structural/regional policy would be dismantled, the process of less developed MS' catching up would probably be slowed downed. Less integration means less solidarity, which equals fewer funds for regional or cohesion policy. Withdrawal from monetary integration could lead to currency wars. Currency rates fluctuations - as stems from Rose effect - negatively influence trade intensity and FDI flows. If the common agricultural policy would be drawn back, also the race for subsidies could occur in agriculture. In the most pessimistic scenario, if also single market would be waived, a sort of trade wars would start. What could be their consequences - was very well described in the literature from the thirties last century. Examples were given by Heckscher (1931) and Bonn (1938) who have used the term integration as an antonym to the disintegration of trade relations in times of trade wars initiated by countries during the Great Depression. Webber (2013) points that it is difficult to speculate in which way the EU might disintegrate. On the other hand, Kelemen (2007) formulates several scenarios of disintegration, from dissolution to (an extreme) civil war. 
If "solidarity" scenarios would prevail, their costs shall also me mentioned. For instance, if those of the MS that so far do have not belonged to the Eurozone, would join it quickly, would probably bear part of the burden associated with financial help for Greece. Thus from their perspective, it is better not to hurry to introduce the euro, till the Eurozone will solve its problems.

With reference to those ideas that envisage the increased role of cities and regions the question can be asked - are they prepared in budgetary and functional terms to bear possible additional tasks and costs? They would be for instance associated with immigrants accommodation and assimilation.

As regards the utopian project of federal, European republic - it may be hard to be accepted by many MS, for whom the sovereignty matters much.

Out of the five scenarios proposed, number 3 seems the most probable. It is multi-speed Europe. The real challenge, if this scenario will evolve, is to safeguard the possibility for the "lagging countries", to join the leaders (more integrated) - if the former will be ready to do so. The challenge is to make the multi-speed Europe - an inclusive concept. Multiple speeds have in fact existed within the EU, as there always have been and will be those who are the laggards and the leaders. Multi-speed approach bears a risk of the "decoupling" of the lagging MS, which could result in disintegration. Integration in the military sphere would be a factor positively contributing to an ever closer integration - reducing the likelihood of scenario 3, and increasing of the scenario 5. Priority on military and defence cooperation would be a strong impetus towards "doing much more together".

The main recommendation stemming from observing the changes that have just started in the $E U$, is to initiate a serious, intensive discussion with the involvement of civil society representatives in the MS, in which the consequences (including pros and cons) of the integration and disintegration scenarios will be elaborated. As suggested by De Wilde \& Zürn (2012) the awareness of the European issues has been increasing. Nevertheless the EU will go through serious changes, consequences of which deserve thorough debate in order to disseminate knowledge on the consequences of the strategic choices ahead of the MS (for instance related to the membership in the Eurozone or remaining outside of it).

Baldwin R. \& Wyplosz Ch. (2004). The Economics of the European Integration. New York: McGraw Hill.

Bonn M.J. (1938). The Crumbling of Empire: The Disintegration of World Economy. London: G. Allen \& Unwin.

Buras, P. (2013). The EU's silent revolution. European Council on Foreign Relations Policy Brief, 87, 1-8.

Cantore, C.M. (2011). We're One, but We're Not the Same: Enhanced Cooperation and the Tension between Unity and Asymmetry in the EU. Perspectives on Federalism, 3(3), 1-21.

debating Europe (2017). Arguments for and against a multi-speed Europe. Retrieved from http://www. debatingeurope.eu/focus/arguments-for-andagainst-a-multi-speed-europe.

De Wilde, P. \& Zürn, M. (2012). Can the Politicization of European Integration be Reversed? Journal of
Common Market Studies, 50(S1), 137-153. https:// doi.org/10.1111/j.1468-5965.2011.02232.x

European Commission (2017). The White Paper on the Future of Europe. Reflections and Scenarios for the EU27 by 2025, Brussels.

Friedman, G. (2015). The European Union, Nationalism and the Crisis of Europe. Geopolitical Weekly, 20.01.2015. Retrieved from https://www. stratfor.com/weekly/european-union-nationalism-and-crisis-europe.

Guerot U. (2016). Warum Europa eine Republik werden muss!: Eine politische Utopie, Dietz Verlag.

Grabbe, H. \& Lehne, S. (2016). How to Build a More Flexible EU After Brexit, Carnegie Europe. Retrieved from http://carnegieeurope.eu/2016/09/08/howto-build-more-flexible-eu-after-brexit-pub-64507.

Hecksher E.F. (1931). Mercantilismen, vols. 2. 
Stockholm: Nordsted (translated by Shapiro M., as: Mercantilism, London 1935, London: Allen \& Unwin; rev. New York: Macmillan, 1955).

Ioannou, D., Leblond P. \& Niemann A. (2015) European integration and the crisis: practice and theory. Journal of European Public Policy, 22(2), 155-176. https://doi.org/10.1080/13501763.2014.994979

Janning, J. (2017). Scenarios for Europe: Deciphering Juncker's White Paper. European Council on Foreign Relations, 3rd March.

Jovanovic M.N. (2005). The Economics of European Integration. Limits and Prospects. Cheltenham, UK, Northampton, MA, USA: Edward Elgar.

Kelemen R.D. (2007). Built to last? The durability of EU federalism. In S. Meunier \& K. McNamara (Eds.), Making History: The State of the European Union, Vol. 8. Oxford: Oxford University Press, 51-66.

Niemann, A. \& Ioannou, D. (2015) European economic integration in times of crisis: a case of neofunctionalism. Journal of European Public Policy, 22(2), 196-218. https://doi.org/10.1080/13501763. 2014.994021
Ortowski W. (2016) Global determinants of Poland's trade during and after the crisis. In K. Gawlikowska-Hueckel, S. Umiński (Eds.), An analysis of Poland's foreign trade in the light of the latest theoretical concepts. Implications for economic policy at time of crisis. (pp. 15-33). Warsaw: Scholar Publishing House.

Piketty T. (2016). Czy można uratować Europę? Warszawa: Wydawnictwo Krytyki Politycznej.

Tosun, J., Wetzel, A. \& Zapryanova, G. (2014) The EU in Crisis: Advancing the Debate. Journal of European Integration, 36(3), 195-211. https://doi.org/ 10.1080/07036337.2014.886401

Webber D., (2013) How likely is it that the European Union will disintegrate? A critical analysis of competing theoretical perspectives. European Journal of International Relations, 20(2) 341-365. https:// doi.org/10.1177/1354066112461286

Zalan, E. (2017). EU's big four back 'multi-speed' Europe. EuObserver. Retrieved from https://euobserver.com/news/137134.

Zielonka J. (2014). Is the EU Doomed? Global Futures. Cambridge: Polity.

\section{About the UMIŃSKI STANISŁAW author Dr. hab. professor \\ The University of Gdańsk, Research Centre on European Integration}

Fields of research interests

International trade, foreign direct investment, European integration

Address

ul. Armii Krajowej 119/121, 81-824 Sopot, Poland

e-mail: uminski@univ.gda.pl 